\title{
Low dose desensitisation does not reduce the toxicity of sulphasalazine in rheumatoid arthritis
}

\author{
I B McInnes, D Porter, E A Murphy, E A Thomson, R Madhok, J A Hunter, T Pullar, \\ H A Capell
}

\begin{abstract}
Objective-To examine the proposal that pretreatment low dose desensitisation may reduce the incidence of toxicity of sulphasalazine in the treatment of rheumatoid arthritis (RA).

Methods-A double blind, placebo controlled trial was performed with 422 patients satisfying the American College of Rheumatology criteria for RA who required sulphasalazine treatment because of increased disease activity. Patients received either sulphasalazine desensitisation, or placebo, for three weeks before commencement of sulphasalazine treatment. The frequency and nature of adverse effects and changes in clinical and laboratory parameters of disease activity were measured after three and six months.
\end{abstract}

Results-Improvement in the efficacy of sulphalasazine (measured by clinical and laboratory parameters) was significant and similar in magnitude in both groups. There was no significant difference between actively and placebo desensitised patients as regards the incidence or profile of adverse effects (toxicity).

Conclusion-Pretreatment low dose desensitisation is unhelpful in reducing the toxicity associated with sulphasalazine treatment of RA.

(Ann Rheum Dis 1996; 55: 328-330)

Centre for Rheumatic Diseases, Glasgow Royal Infirmary, Glasgow, United Kingdom

I B McInnes

D Porter

E A Murphy

E A Thomson

R Madhok

H A Capell

Gartnavel General Hospital, Glasgow, United Kingdom

J A Hunter

Ninewells Hospital, Dundee, United Kingdom

T Pullar

Correspondence to: I B McInnes,

Centre for Rheumatic

Diseases, Glasgow Royal

Infirmary, 10 Alexandra

Parade, Glasgow G31 2ER

United Kingdom.

Accepted for publication

22 January 1996
Sulphasalazine is widely used as a second line agent for the treatment of rheumatoid arthritis (RA). Current dose regimens usually commence at $500 \mathrm{mg} /$ day, and thereafter use a progressive increase in dose by $500 \mathrm{mg} /$ day increments to a target dose of $40 \mathrm{mg} / \mathrm{kg}^{1}$ However, toxicity (particularly mucocutaneous and gastrointestinal adverse effects) remains a relatively common reason for discontinuation of treatment in the first year, in contrast to failed efficacy, which is the predominant cause of discontinuation of treatment at a later stage. ${ }^{2-6}$

The beneficial effect of desensitisation with low dose sulphasalazine over three weeks was reported in an open uncontrolled trial that examined the effect of reintroduction of sulphasalazine in patients who had previously experienced mucocutaneous toxicity with this drug. ${ }^{7}$ Patients who tolerate sulphasalazine achieve improvement in clinical and laboratory indices of disease activity and over one year may reduce the progression of erosive damage. ${ }^{8-11}$ Thus an approach that reduces sulphasalazine toxicity would represent an attractive option offering therapeutic advantage in the treatment of RA. We have studied, therefore, the effect of an initial course of desensitisation in patients with rheumatoid arthritis receiving sulphasalazine in a double blind, placebo controlled trial.

\section{Patients and methods}

Approval for the study was obtained from the local Ethics Committees. We recruited 422 patients satisfying the American College of Rheumatology criteria for rheumatoid arthritis $^{12}$ and attending routine outpatient clinics, from three Scottish hospitals in two cities (245 from Glasgow Royal Infirmary; 130 from Gartnavel General Hospital, Glasgow; 47 from Ninewells Hospital, Dundee).

Patients were allocated randomly to receive either sulphasalazine desensitisation (standard kit, Pharmacia) or placebo (ascorbic acid) for three weeks before commencement of their sulphasalazine treatment (enteric coated) by our standard dosage regimen ${ }^{1}$ - enteric coated sulphasalazine $500 \mathrm{mg} /$ day for one week, increased in $500 \mathrm{mg}$ weekly increments to the target dose of $40 \mathrm{mg} / \mathrm{kg}$ body weight or until side effects supervened. Desensitisation involved a programme of slowly increasing doses of sulphasalazine from $1 \mathrm{mg} /$ day up to $800 \mathrm{mg} /$ day over three weeks.

Basic demographic data were collected at the outset (age, gender, disease duration, rheumatoid factor positivity). Clinical and laboratory parameters were assessed at the start of the conventional sulphasalazine regimen and three and six months later (morning stiffness, visual analogue pain score, modified Health Assessment Questionnaire (HAQ), erythrocyte sedimentation rate (ESR), $C$ reactive protein, leucocyte count, haemoglobin, platelets), and all adverse effects were documented over a six month period (all 375 patients at the two Glasgow hospitals were seen by one metrologist, EAT). Clinicians administering care were blinded to the group to which the patient was allocated. Symptomatic treatment of nausea with oral prochlorperazine was allowed in each treatment arm. No patient had previously received sulphasalazine, though other second line drugs had been administered to many of the patients before they entered the study. Patients did not receive oral corticosteroids, though intra-articular steroid was allowed. 
Table 1 Disease activity characteristics over six months

\begin{tabular}{|c|c|c|c|c|}
\hline & \multicolumn{2}{|l|}{ Active } & \multicolumn{2}{|l|}{ Placebo } \\
\hline & 0 months* & 6 months* & 0 monthst & 6 monthst \\
\hline $\begin{array}{l}\text { Pain score (scale } 0-4) \\
\text { Morning stiffness (minutes) } \\
\text { HAQ score } \\
\text { Haemoglobin }(g / 1) \\
\text { Leucocytes }\left(\times 10^{9} / 1\right) \\
\text { Platelets }\left(\times 10^{9} /\right) \\
\text { ESR }(\mathrm{mm} / 1 \mathrm{st} \mathrm{h}) \\
\text { CRP }(\mathrm{mg} / \mathrm{l})\end{array}$ & $\begin{array}{c}3 \cdot 0(1-4) \\
60(0-720) \\
1 \cdot 875(1 \cdot 25-2 \cdot 875) \\
123(82-160) \\
8 \cdot 3(3 \cdot 5-10) \\
342(149-825) \\
41(4-50) \\
27(<10-233)\end{array}$ & $\begin{array}{c}2 \cdot 0(1-4) \\
30(0-720) \\
1 \cdot 750(1-3) \\
124(76-160) \\
6 \cdot 9(3 \cdot 9-6) \\
285(121-704) \\
23 \cdot 5(1-150) \\
10(<10-148)\end{array}$ & $\begin{array}{c}3 \cdot 0(1-4) \\
60(0-720) \\
1 \cdot 625(1-3) \\
124(83-164) \\
8 \cdot 0(3 \cdot 5-14 \cdot 2) \\
331(45-999) \\
43(0-150) \\
22 \cdot 5(<10-207)\end{array}$ & $\begin{array}{c}2 \cdot 0(1-4) \\
30(0-720) \\
1 \cdot 625(1-3) \\
125(92-163) \\
6 \cdot 8(2 \cdot 7-7) \\
278(102-589) \\
20(1-120) \\
10(<10-113)\end{array}$ \\
\hline
\end{tabular}

Values are median (range).

$\mathrm{HAQ}=$ Health assessment questionnaire; $\mathrm{ESR}=$ erythrocyte sedimentation rate; $\mathrm{CRP}=\mathrm{C}$ reactive protein.

No significant difference between active and placebo groups.

${ }^{\star}$ Active 0 months $v 6$ months: $\mathrm{p}<0.01-\mathrm{p}<0.001$ (except haemoglobin: $\mathrm{p}=\mathrm{NS}$ )

†Placebo 0 months $v 6$ months: $\mathrm{p}<0.01-\mathrm{p}<0.001$ (except haemoglobin: $\mathrm{p}=\mathrm{NS}$ ).

\section{STATISTICS}

Assuming a risk of $25 \%$ of adverse effects using no desensitisation, power calculations showed that a trial with $90 \%$ chance of showing a reduction in risk to $12.5 \%$ (that is, a $50 \%$ reduction in the risk) at significance $\mathrm{p}<0.05$, would require 199 patients per treatment group. The trial was not of sufficient power to detect smaller improvements (for example $25 \%$ reduction) in the risk of adverse effects, or a reduction in the incidence of individual side effects such as rash. Significance of changes in parameters was tested within groups with the Wilcoxon matched pairs signed ranks test and between groups with the MannWhitney test. Incidence of adverse effects was analysed with Fisher's exact test.

\section{Results}

The active and placebo desensitised groups were well matched for demographic characteristics (age, disease duration, gender, and rheumatoid factor positivity) and for initial measures of disease activity (table 1 ).

Significant improvements in clinical indices including pain score, duration of morning stiffness and HAQ, and in laboratory parameters including ESR, C reactive protein, and platelet count, were seen in both active and placebo treatment groups at three and six months (Wilcoxon). There was no significant change in haemoglobin (Wilcoxon). There was no significant difference between the two groups in the degree of change for any disease activity parameter (Mann-Whitney) (table 1).

Table 2 lists the reasons for discontinuation of treatment. As expected, most patients who stopped treatment did so because of an adverse effect rather than failed efficacy: 39 of 211 patients $(18.5 \%$ (95\% confidence interval (CI) 13.3 to $23 \cdot 7 \%$ )) in the active desensitisation group and 49 of 211 patients $(23.2 \%(95 \% \mathrm{CI}$ 17.5 to $28.9 \%$ )) in the placebo group experienced adverse effects necessitating discontinuation of treatment within six months. The difference in the rate of adverse effects was $4 \cdot 7 \%$ (95\% CI $3 \cdot 1$ to $12 \cdot 5 \%$; not significant). Table 3 shows the clinical and laboratory characteristics of these side effects. Although fewer patients in the actively treated group discontinued treatment because of nausea and vomiting, there were more cases of diarrhoea and mouth ulceration in these patients, and total adverse effects in each group therefore occurred with similar frequency. Transient adverse effects that did not require cessation of treatment were also recorded and similarly demonstrated no significant difference between groups. Several patients developed more than one adverse effect; each was treated as a separate event (table 4). The

Table 2 Clinical outcome of treatment

\begin{tabular}{lcc}
\hline & $\begin{array}{l}\text { Active } \\
\text { desensitisation } \\
(n=211)\end{array}$ & $\begin{array}{l}\text { Placebo } \\
\text { desensitisation } \\
(n=211)\end{array}$ \\
\hline Discontinued treatment & $(53)$ & $(64)$ \\
$\quad$ Lack or loss of effect & 1 & 2 \\
Intercurrent illness & 2 & 3 \\
Non-compliance & 6 & 7 \\
Moved away & 2 & 0 \\
Died (not drug related) & 3 & 3 \\
Adverse effect & 39 & 49 \\
Continued treatment & $(158)$ & $(147)$ \\
No adverse effect & 72 & 82 \\
Transient adverse effect & 86 & 65 \\
\hline
\end{tabular}

No significant difference between active and placebo groups.

Table 3 Details of adverse effects occurring in desensitised and placebo groups and leading to discontinuation of treatment

\begin{tabular}{lcc}
\hline & Active & Placebo \\
\hline Nausea / vomiting / anorexia & 14 & 25 \\
Diarrhoea & 4 & 1 \\
Abdominal pain & 4 & 1 \\
Rash & 7 & 9 \\
Mouth ulcers & 3 & 0 \\
Lymphadenopathy & 1 & 0 \\
Leucopenia & 2 & 5 \\
Headaches & 0 & 3 \\
Dizziness & 2 & 2 \\
Hepatic function abnormality & 0 & 3 \\
Malaise & 1 & 0 \\
Anxiety / depression & 1 & 0 \\
\hline
\end{tabular}

No significant difference between active and placebo groups.

Table 4 Number of transient adverse events occurring in desensitised and placebo groups

\begin{tabular}{lll}
\hline & Active & Placebo \\
\hline Nausea / vomiting / anorexia & 57 & 36 \\
Diarrhoea & 13 & 8 \\
Rectal bleed & 1 & 0 \\
Constipation & 2 & 0 \\
Abdominal pain & 0 & 1 \\
Rash & 4 & 4 \\
Candida infection & 1 & 0 \\
Itch & 0 & 6 \\
Mouth ulcers & 6 & 6 \\
Thrombocytopenia & 0 & 1 \\
Leucopenia & 1 & 3 \\
Epistaxis & 1 & 1 \\
Headaches & 5 & 3 \\
Dizziness & 3 & 3 \\
Hepatic function abnormality & 2 & 1 \\
Proteinuria / haematuria & 2 & 4 \\
Anxiety / depression & 1 & 0 \\
\hline
\end{tabular}

No significant difference between active and placebo groups. 
overall incidence of adverse effects, whether transient or leading to discontinuation of drug, was similar in each group: $65.8 \%$ in patients desensitised actively and $61 \cdot 1 \%$ in those receiving placebo.

\section{Discussion}

Toxicity remains the major limiting factor in the use of disease modifying anti-rheumatic drugs (DMARDs) in treatment of rheumatoid arthritis. This issue is particularly pertinent because the use of DMARDs is advocated at an early stage in disease progression, at a time when the prognosis is unclear and, accordingly, the risk/benefit ratio of treatment is less distinct than that for treatment of patients with advanced, well characterised disease. Previous studies indicate that sulphasalazine is comparable to other DMARDs in both its toxicity profile and its efficacy. ${ }^{2} 4910$ Increasingly, it is offered to patients with inflammatory disease without the supervision of specialist clinics. In this study we have investigated the possible role of drug desensitisation for reduction of the early adverse effects that often lead to discontinuation of sulphasalazine treatment, thereby allowing greater therapeutic benefit to be obtained from its use in the treatment of RA.

In order to demonstrate a reduction in adverse events, even when these occur relatively commonly, large numbers of patients are required. Although power calculations indicated a priori that our study possessed the requisite sample size to detect a $50 \%$ reduction in adverse effects up to six months, it is unlikely that the trial could have detected a smaller (for example $25 \%$ ) reduction in risk, or a reduction in individual side effects such as rash. However, even though the present study did not have the statistical power to exclude an effect of low dose desensitisation for subgroups of toxicity, no trend towards a difference in mucocutaneous events (rash, mouth ulcers) was observed. As the positive effects of desensitisation are likely to be evident soon after commencement of drug treatment, it seems unlikely that an effect would be manifest in a longer study. The observed reduction in nausea and vomiting as a cause of discontinuation did not significantly alter outcome, because the frequency of other adverse effects was increased in the actively desensitised group. No significant differences were observed, even when transient adverse effects were included in the analysis. The number of idiosyncratic adverse effects was too small to allow statistical analysis, even in a study of this size, and so an effect of desensitisation on these cannot be excluded. Empirically, however, it seems unlikely that events of this nature would be affected by an alteration of dose loading.

This trial should not dissuade clinicians from attempting desensitisation after mucocutaneous toxicity has occurred, because the evidence suggests that this is effective. ${ }^{7}$ However, the study does argue against the routine use of prior low dose desensitisation. This is disappointing, because, though several DMARD options are available to patients early in the management of their RA, the requirement for a longer term view of treatment bestows upon the clinician the responsibility to maximise the usefulness of each drug used. In our clinical practice, we manage non-serious gastrointestinal or mucocutaneous toxicity by reduction of the dose of sulphasalazine, or transient withdrawal of sulphasalazine, pending resolution of toxicity. At this point, desensitisation or reintroduction of sulphasalazine at $500 \mathrm{mg} /$ day is attempted, with close clinical monitoring. Serious mucocutaneous, gastrointestinal or marrow related toxicity leads to final cessation of sulphasalazine treatment.

This study confirms the clinical efficacy of sulphasalazine, at a level comparable to that of other DMARDs, as reported in previous studies. $^{910}$ Interestingly, the placebo and actively treated groups displayed similar efficacy at three and six months, indicating that no therapeutic advantage was conferred by the additional three weeks treatment received by the active group, albeit with an extremely low dose of the drug.

In conclusion, our data do not support a positive benefit from low dose sulphasalazine pretreatment desensitisation in reducing the toxicity experienced during initiation of treatment of rheumatoid arthritis. A type 2 error remains a possibility, but small reductions in the risk of non-serious adverse effects are probably not clinically significant.

We would like to thank Pharmacia for providing the desensitisation kits, Miss Ann Tierney for typing the manuscript, and Mrs Dorothy McKnight for help with computing.

1 Pullar T, Hunter J A, Capell H A. Sulphasalazine in the treatment of rheumatoid arthritis: relationship of dose and serum levels to efficacy. $B r \mathcal{F}$ Rheumatol 1985; 24: 269-76.

2 Capell H A, Porter D, Madhok R, Hunter J A. Second line (disease modifying) treatment in rheumatoid arthritis: which drug for which patient? Ann Rheum Dis 1993; 52: 423-8.

3 Grindulis K A, McConkey B. Outcome of attempts to treat rheumatoid arthritis with gold, penicillamine, sulphasalazine, or dapsone. Ann Rheum Dis 1984; 43: 398-401.

4 Situnayake R D, Grindulis K A, McConkey B. Long term treatment of rheumatoid arthritis with sulphasalazine, gold or penicillamine: a comparison using life-table methods. Ann Rheum Dis 1987; 46: 177-83.

5 Amos R S, Pullar T, Bax D E, Situnayake D, Capell H A, McConkey B. Sulphasalazine for rheumatoid arthritis: toxicity in 774 patients monitored for one to eleven years. $B M F$ 1985; 293: 420-5.

6 Marabani M, Madhok R, Capell H A, Hunter J A. Leucopenia during sulphasalazine treatment for rheumatoid arthritis. Ann Rheum Dis 1989; 48: 505-7.

7 Bax D E, Amos R S. Sulphasalazine in rheumatoid arthritis; desensitising the patient with a skin rash. Ann Rheum Dis desensitising the pati

8 Pullar T, Hunter J, Capell H A. Effect of sulphasalazine on the radiological progression of rheumatoid arthritis. Ann Rheum Dis 1987; 46: 398-402.

9 Felson D, Anderson J J, Meenan R F. The comparative efficacy and toxicity of second-line drugs in rheumatoid arthritis. Arthritis Rheum 1990; 33: 1449-59.

10 Porter D R, McInnes I B, Hunter J, Capell H A. Outcome of second line therapy in rheumatoid arthritis. Ann Rheum Dis 1994; 53: 812-5.

11 Van der Heijde D M F M, Van Riel P, Nuver-Zwart I van de Putte L. Effects of hydroxychloroquine and sulphasalazine on the progression of joint dame in theumatoid arthritis. Lancet 1989; 335: 1036-8.

12 Arnett F C, Edworthy S M, Bloch D A, et al. The American Rheumatism Association 1987 revised criteria for the classification of rheumatoid arthritis. Arthritis Rheum 1988; 31: 315-24. 